\title{
A CIRURGIA DE TRANSGENITALIZAÇÃO E SEUS REFLEXOS NO DIREITO
}

\author{
Patrícia Fortes Attademo Ferreira* \\ Lucas Cardoso Jardim**
}

SUMÁRIO: Introdução; 2 Breves Considerações Sobre o Ponto de Vista Médico; 3 As Consequências da Cirurgia de Transgenitalização na Seara Penal; 4 As Consequências da Cirurgia de Transgenitalização na Seara Civil; 4.1 Efeitos da Transgenitalização no Registro Civil; 4.2 Efeitos da Transgenitalização no Casamento e Filiação; 5 Conclusão; Referências.

RESUMO: A condição transexual, bem como seu tratamento mais extremo e notório, a cirurgia de transgenitalização, chamam a atenção na sociedade moderna por gerar situações singulares na seara forense que pedem um tratamento legal direcionado especificamente a elas. Em reflexo disso, há uma tendência jurídica mundial em reconhecer os direitos do transexual, legislando sobre o tema de forma a salvaguardarlhes a identidade, a dignidade, a saúde, etc. Como o Brasil ainda não se juntou a essa onda legislativa, os reflexos jurídicos da cirurgia de transgenitalização são vistos dentro dos limites de normas infraconstitucionais que não abarcam os transexuais, limites estes que serão abordados aqui, por meio de revisão aos próprios textos legais e à doutrina acerca do tema.

PALAVRAS-CHAVE: Alteração de Registro Civil; Cirurgia de Transgenitalização; Responsabilidade Penal; Transexualismo.

\section{TRANSGENITALIZATION SURGERY AND ITS LEGAL CONSEQUENCES}

ABSTRACT: The trans-sexual condition and its notorious treatment, transgenitalization surgery, impacts modern society, due to the special situations in law which demand specifically directed legal treatments. A juridical trend is extant worldwide on the acknowledgement of trans-sexual rights legislated to warrant their identity, dignity, health and other factors. Since Brazil has still to adapt itself to these laws, the juridical reflections on transgenitalization surgery are seen within the limits of infra-constitutional norms which do not include transsexual people. Limits are dealt with in current analysis by reviewing the legal texts and the doctrine on the theme.

\footnotetext{
Docente da Universidade do Estado do Amazonas (UEA); Doutoranda em Ciências Jurídicas pela Universidad Castilha La Mancha - Espanha; E-mail: patriciaattademo@hotmail.com

** Graduação em Direito pela Universidade do Estado do Amazonas (UEA), Brasil
} 
KEY WORDS: Transexualism; Transgenitalization Surgery; Penal Responsibility; Changes In The Birth Certificate.

\section{LA CIRUGÍA DE REASIGNACIÓN DE GÉNERO Y SUS REFLEJOS EN EL DERECHO}

RESUMEN: La condición transexual, bien como su tratamiento más extremo y notorio, la cirugía de reasignación de género, llaman la atención de la sociedad moderna por generar situaciones singulares en el ámbito forense que piden un tratamiento legal direccionado específicamente a ellas. En función de eso, hay una tendencia jurídica mundial en reconocer los derechos del transexual, legislando sobre el tema de forma a salvaguardarles la identidad, la dignidad, la salud, etc. Como Brasil todavía no se sumó a esa ola legislativa, los reflejos jurídicos de la cirugía de la reasignación de género son vistos en los límites de las normas infra constitucionales que no abarcan los transexuales, límites esos que serán abordados aquí, por medio de la revisión de los propios textos legales y la doctrina sobre el tema.

PALABRAS-CLAVE: Transexualismo; Cirugía de reasignación de género; Responsabilidad Penal; Alteración del Registro Civil.

\section{INTRODUÇÃO}

As questões acerca dos transexuais, por abarcarem aspectos jurídicos, médicos e sociais, são um terreno fértil a ser explorado pela bioética, vez que através dela pode-se vislumbrar um futuro mais adequado a essas pessoas, futuro este em que sua condição é analisada de um ponto de vista macroscópico e seus direitos, garantidos de forma mais ampla, sem amarras anacrônicas de qualquer espécie.

Primeiramente, com o princípio da dignidade humana permitindo à pessoa o livre desenvolvimento de sua personalidade e o direto à saúde resguardando o bem-estar físico e psíquico do indivíduo, entende-se que a Constituição Federal de 1988 provê a base à garantia à cirurgia de transgenitalização, isto é, a cirurgia que redesigna o sexo biológico do paciente de forma que este se torne compatível com seu sexo psíquico, a prévia incompatibilidade entre eles sendo o cerne da condição transexual. 
No entanto, esta cirurgia gera um número de reflexos jurídicos específicos, que serão tratados no decorrer do artigo.

\section{BREVES CONSIDERAÇÕES SOBRE O PONTO DE VISTA MÉDICO}

O Código Civil Brasileiro de 2002 prevê, em seu art. 13, que "salvo por exigência médica, é defeso o ato de disposição do próprio corpo, quando importar diminuição permanente da integridade física, ou contrariar os bons costumes”, de forma que faz-se necessário compreender o caráter da medida pelo viés da medicina.

A priori, ainda diante do quadro de um transexual adulto diagnosticado, não promove-se pela mudança de sexo indiscriminada e em inobservância dos procedimentos médicos adequados. Renato Pamplona da Costa apud Szaniaswki ${ }^{1}$ elenca os exames multidisciplinares que devem ser feitos antes de uma intervenção cirúrgica ser cogitada: primeiramente, há a necessidade de se confirmar o transexualismo do indivíduo, que não se restringe ao mero exame da genitália da pessoa. Este exame, claro, faz-se mister, porém se trata de um exame de caráter preliminar, que busca averiguar se a genitália é definida, se é capaz de cumprir suas funções biológicas, ou se é subdesenvolvida e/ou ambígua, configurando hermafroditismo. Numa segunda etapa, examina-se também a pilosidade do indivíduo ${ }^{2}$.

A seguir, procede-se à análise de genitália interna do paciente, quando se averigua se esta corresponde à genitália externa. Se sim, sua capacidade de cumprir sua função biológica é avaliada. Se constatada, o médico tem definido o sexo biológico do paciente e deve verificar se este corresponde ao seu sexo psíquico. Caso negativo, conclui-se que o paciente tem indícios de transexualismo ${ }^{3}$.

Examinam-se, então, os hormônios do paciente, para saber se são predominantemente masculinos ou femininos. Nos transexuais masculinos, realizase também um espermatograma. Neste caso, um número de espermatozoides reduzido costuma ser identificador de disforia de gênero no paciente. Mais adiante, faz-se o exame hispatológico do material colhido no testículo ou no clitóris e, por fim, há o exame psicológico do paciente, a fim de avaliar em torno de qual verve

\footnotetext{
1 SZANIAWSKI, Elimar. Limites e possibilidades do direito de redesignação do estado sexual. São Paulo: Revista dos Tribunais, 1998, p. 65 e ss., e 126 e ss.

2 COSTA, Renato Pamplona da. Os onze sexos. São Paulo: Gente, 1997, p. 167.

3 SZANIAWSKI, Elimar. Op. cit.
} 
a personalidade do indivíduo tende a orbitar, se masculina ou feminina. Perguntas sobre sua identidade de gênero e sobre suas práticas e relações sexuais entram em cena nesta etapa para que seu sexo psíquico possa ser determinado. Se, após todos esses exames, for constatada a disforia de gênero, ou fortes indícios da mesma, recomenda-se que o paciente faça alguma modalidade de terapia psiquiátrica ${ }^{4}$.

Após a terapia, caso não reste identificado nenhum outro distúrbio psíquico e confirmem-se os resultados dos exames previamente realizados, este paciente tratar-se-á de um transexual primário, aquele para o qual a cirurgia é uma solução recomendável, porém isto também não deve fazer pressupor a imediata necessidade de intervenção cirúrgica para este indivíduo. Szaniaswki elenca quatro terapias que podem, simultânea ou sucessivamente, ser aplicadas no paciente diagnosticado como transexual primário: a terapia medicamentosa, a terapia hormonal, a terapia psicopedagógica e a terapia psiquiátrica 5 .

Vale ressaltar também que muitos transexuais optam por nunca fazer a operação, remanescendo somente travestidos, e em nenhum momento acreditase que esta discricionariedade lhes deva ser tolhida. Acredita-se, porém, que, após anos de extensivos exames e de métodos infrutíferos de amenizar os efeitos da condição por meio de terapia, durante os quais o transexual padecerá do sofrimento inerente à discrepância entre os sexos biológico e psíquico e à vontade irredutível de mudar de sexo biológico, não há como negar a exigibilidade médica da cirurgia de transgenitalização, ressalvando o seu caráter derradeiro na busca da saúde psicológica do paciente. Entende-se que, se e alterar o sexo psíquico para se adequar ao sexo biológico resta impossível por meio dos métodos disponíveis, então a única opção remanescente é a alteração do biológico para se adequar ao psíquico.

Com o passar dos anos, assim também entendeu a comunidade médica, o que levou à publicação da Resolução no 1.482/97 do Conselho Federal de Medicina, que autorizava, a título experimental, a cirurgia de transgenitalização consentida em transexuais maiores de 21 (vinte e um) anos, medicamente diagnosticados, que tivessem sido acompanhados pelo período de dois anos por equipe multidisciplinar constituída por médico-psiquiatra, cirurgião, psicólogo e assistente social e não possuíssem nenhuma característica física imprópria à cirurgia. Esta resolução restringia a realização de tal procedimento a hospitais universitários ou públicos adequados à pesquisa ${ }^{6}$.

6 Resolução n ${ }^{0}$ 1.482/97, Conselho Federal de Medicina. Disponível em: http://www.portalmedico.org.br/resolucoes/CFM/1997/1482_1997.htm Acesso em: 29 maio. 2012. 
Em 2002, a referida instituição publicou a Resolução $\mathrm{n}^{0}$ 1.652/02, que revoga a Resolução $\mathrm{n}^{0} 1.482 / 97$, retirando o caráter experimental da cirurgia de transgenitalização do tipo neocolpovulvoplastia (transformação do pênis em neovagina), aceitando-a como uma técnica consolidada de tratamento de casos de transexualismo, no entanto, mantendo o referido caráter na cirurgia do tipo neofaloplastia (transformação de vagina em neopênis). A resolução estipula que, para o diagnóstico de transexualismo, outros distúrbios mentais devem ser afastados (em consonância com as conclusões científicas de que o transexualismo é um distúrbio próprio que não implica necessariamente - tampouco exclui - a existência de outros), bem como inclui um endocrinologista no rol dos profissionais que devem constar na equipe multidisciplinar responsável pelo acompanhamento do paciente (levando em consideração a necessidade dos exames de taxas hormonais necessários ao diagnóstico do transexualismo). Uma vez que tirava a cirurgia para os transexuais masculinos da esfera do experimentalismo, a publicação permitia a realização do procedimento em hospitais privados, ao mesmo tempo em que mantinha restrita aos hospitais universitários ou públicos adequados à pesquisa a realização de cirurgia para os transexuais femininos ${ }^{7}$.

O órgão versou novamente sobre o tema na Resolução $\mathrm{n}^{0}$ 1.955/2010, que revoga a Resolução ${ }^{0}$ 1.652/02 e, em suma, mantém o texto desta, porém alterando-o no tocante aos locais onde é permitida a realização da cirurgia de neofaloplastia. A redação mais moderna não faz restrições entre hospitais públicos e privados para qualquer dos procedimentos, conquanto estejam presentes os prérequisitos estabelecidos pela instituição, estes sendo que o hospital tenha equipe multidisciplinar completa, prevista em regimento interno, com corpo clínico inscrito no Conselho Regional de Medicina, e com Comissão de Ética constituída e funcional, nos termos da legislação pertinente ${ }^{8}$.

\section{AS CONSEQUÊNCIAS DA CIRURGIA DE TRANSGENITALIZAÇÃO NA SEARA PENAL}

A intervenção cirúrgica em casos de transexualismo possui efeitos jurídicos, majoritariamente, em duas esferas: a penal e a civil. No Direito Penal, a maior

\footnotetext{
Resolução $\mathrm{n}^{0} 1.652 / 02$, Conselho Federal de Medicina. Disponível em: http://www.portalmedico.org.br/resolucoes/CFM/2002/1652 2002.htm Acesso em: 29 maio. 2012.

8 Resolução $n^{0}$ 1.955/2010, Conselho Federal de Medicina. Disponível em: http://www.portalmedico.org.br/ resolucoes/CFM/2010/1955_2010.htm Acesso em: 29 maio. 2012.
} 
discussão suscitada por ela orbita em volta da sua configuração ou não como delito. No Direito Civil, tal operação afeta as leis relacionadas aos registros, bem como as que versam sobre Direito das Famílias.

$\mathrm{Na}$ seara penal, diz-se crime do ato típico, ilícito e culpável, ou seja, uma conduta prevista em lei, que incorre em afronta ao direito material e pela qual imputa-se a responsabilidade?

No tocante à cirurgia de transgenitalização, a primeira controvérsia a ser dirimida diz respeito à possibilidade de enquadramento do procedimento, que, em essência, implica na perda permanente de um membro do paciente, no caso, os órgãos sexuais primários, no crime de lesão corporal de natureza grave, previsto no art. $129, \S 2^{\circ}$, III, do Código Penal.

Inicialmente, entende-se que a cirurgia consentida não configura ofensa ao Direito, pois trata-se de uma medida de caráter benéfico ao paciente, que melhorará sua qualidade de vida ao afastá-lo das condições psicológicas frágeis causadas pelo transexualismo, e que a cirurgia não consentida, realizada com dolo, não objetivando tal nobre fim, seja alvo de tipificação.

A figura do estado de necessidade pode ser invocada, em certos casos, para justificar certos procedimentos cirúrgicos não consentidos quando sobrevierem situações emergenciais em que o decurso do tempo necessário para se obter consentimento próprio ou dos familiares porá em risco a vida do paciente, nos termos do art. $146, \S 3^{\circ}$, I, do Código Penal. No entanto, como visto anteriormente, a previsão de cirurgia de transgenitalização é antecedida por uma miríade de exames, bem como pelo acompanhamento por equipe multidisciplinar por dois anos, de forma que não há espaço, in casu, para falar-se em estado de necessidade como justificativa para uma cirurgia de transgenitalização não consentida ${ }^{10}$.

Szaniawski, baseado nos entendimentos de penalistas como Heleno Cláudio Fragoso e Júlio Mirabete, arremata:

Embora a maioria dos autores afaste a figura do consentimento do paciente, no âmbito penal, como pressuposto de exclusão da antijuridicidade das operações cirúrgicas de ablação de órgãos e membros, quando o interesse a ser protegido transcende a esfera privada, são admitidos como requisitos válidos a ausência de dolo, a ausência de tipicidade e a presença do estado de necessidade. Deste modo, a doutrina brasileira, na sua maioria, tem entendido no sentido de que esta modalidade de intervenção cirúrgica não constitui crime ${ }^{11}$.

\footnotetext{
$\overline{9}$ NUCCI, Guilherme de Souza. Código penal comentado. São Paulo: Revista dos Tribunais, 2006, p. 118.

${ }^{10}$ SZANIAWSKI, Elimar. Op. cit.

11 SZANIAWSKI, Elimar. Op. cit.
} 
Aduz-se, então, que o entendimento doutrinário se mostre favorável à inclusão do consentimento do paciente no rol dos excludentes de ilicitude nesses casos, fato é que o ordenamento pátrio não contemplou sua presença no referido rol, deixando a pertinente discussão em aberto.

Sobre o tema Tereza Rodrigues Vieira entende que:

Adequar o sexo não é uma questão de querer, mas de estar habilitado. Normalmente, os transexuais querem se beneficiar do duplo tratamento: endocrinológico e cirúrgico. O puro e simples consentimento do paciente não será suficiente para fazer cair por terra o princípio da integridade física. Para que tal fato ocorra este deverá estar atrelado a necessidade terapêutica comprovada ${ }^{12}$.

Considerando a seriedade e irreversibilidade da intervenção, concorda-se com o posicionamento da douta jurista no que concerne aos critérios e cuidados que devem ser tomados no período que antecede o procedimento.

\section{AS CONSEQUÊNCIAS DA CIRURGIA DE TRANSGENITALIZAÇÃO NA SEARA CIVIL}

A maior parte dos efeitos jurídicos, no entanto, dá-se em esfera civil, pois é neste ramo do direito que questões relativas à personalidade do indivíduo encontram suas respectivas previsões legais. Nesta esfera, o transexual operado luta pelo pleno reconhecimento de sua nova identidade, que configura sua maior luta após a cirurgia. Outras questóes controversas, como as relativas ao seu casamento e filiação, também são arguidas em Juízos Cíveis e serão abordadas mais adiante.

\subsection{EFEITOS DA TRANSGENITALIZAÇÃO NO REGISTRO CIVIL}

A cirurgia de transgenitalização, como supramencionado, tem por objetivo a adequação do sexo morfológico do paciente em relação ao seu sexo psíquico. Uma vez realizada e estabelecido o regime hormonal que adequará, também, o sexo endócrino ao psíquico, surge a problemática de adequação do sexo jurídico.

Com a mudança do gênero, o nome do indivíduo passa a não mais corresponder à sua pessoa, tornando obsoleto seu registro civil, bem como todos os documentos que o usaram como base.

12 VIEIRA, Tereza Rodrigues. Aspectos psicológicos, médicos e jurídicos do transexualismo. In: PSICÓLOGO informação, no 4. São Paulo: Metodista Digital, 2000, p. 75. 
Entende-se que o artigo 58 da Lei de Registros Públicos, ao impor a imutabilidade do prenome com base na manutenção da ordem pública, verdadeiramente perpetua a condição psicológica do transexual, na medida em que este continua a ver-se impedido de realizar seu maior anseio, que é o de ser aceito na sociedade de posse do gênero que toma por próprio.

No entanto, uma interpretação extensiva do artigo 55, parágrafo único, da mesma lei, oferece outra disposição, in verbis:

Art. 55. Quando o declarante não indicar o nome completo, o oficial lançará adiante do prenome escolhido o nome do pai, e na falta, o da mãe, se forem conhecidos e não o impedir a condição de ilegitimidade, salvo reconhecimento no ato.

Parágrafo único. Os oficiais do registro civil não registrarão prenomes suscetíveis de expor ao ridículo os seus portadores. Quando os pais não se conformarem com a recusa do oficial, este submeterá por escrito o caso, independente da cobrança de quaisquer emolumentos, à decisão do Juiz competente.

Dele, pode-se aduzir que há uma preocupação legal em poupar o portador do nome de situações vexatórias, ainda que não expressa claramente no texto da lei. Neste sentido, decidiu a Segunda Câmara Cível do Tribunal de Justiça do Paraná:

[...], há de se considerar o aspecto da subjetividade, pois o que é natural para uns, pode ser constrangedor para outros. Na verdade, somente o indivíduo que o carrega é capaz de mensurar a satisfação ou o constrangimento que o seu prenome lhe causa. No caso de autos, a autora alega que sofre inúmeros constrangimentos em razão do prenome ser masculino. Diz que vive em constante tristeza e possui muita vergonha quando é obrigada a falar seu nome verdadeiro. A prova testemunhal confirma a versão da apelante, haja vista que a testemunha Luzia Tenório Cavalcanti disse conhecer a autora há oito anos, que sempre a chamou de Helena e que veio a saber há pouco tempo que seu nome era Jorandir, ocasião em que presenciou o constrangimento pelo qual passou a autora no momento em que foi chamada pelo seu nome verdadeiro em uma consulta no posto de saúde ${ }^{13}$.

Aduz-se que isto advém do fim social inerente à atividade jurídica, que encontra previsão no art. $5^{\circ}$ da Lei de Introdução ao Código Civil Brasileiro, in verbis: "Na aplicação da lei, o juiz atenderá aos fins sociais a que ela se dirige e às exigências do bem comum".

13 VIEIRA, Tereza Rodrigues. Nome e sexo: mudanças no registro civil. São Paulo: Revista dos Tribunais, 2008, p. 165. 


\section{Neste diapasão, Tereza Rodrigues Vieira assevera:}

Não deve a imutabilidade do prenome ser compreendida em caráter absoluto, pois injusto seria se, em homenagem ao texto da lei, se forçasse um indivíduo a usar um prenome capaz de expô-lo ao sarcasmo. As pessoas hão de se conscientizar de que a lei é necessária para servir ao homem e não para oprimi-lo ${ }^{14}$.

\section{Da mesma forma, Ézio Pereira entende que:}

Decerto, a alteração ou a retificação cuja causa petendi é a 'exposição ao ridículo', deve ser analisada como uma interpretação sistemática/contextual, teleológica, histórica, agregada a uma profunda sensibilidade, afastando-se de formalismos, de tecnicismos ortodoxos e obsoletos, que não condizem com o pensamento jurídico contemporâneo, onde o enfoque maior são os direitos humanos, a dignidade da pessoa humana, os sublimes valores que enaltecem o ser humano enquanto tal. [...]

A tutela da pessoa não pode ser fragmentada e setorizada em modelos legais concretos estanques. O ser humano, a sua vida, os seus sentimentos, os seus afetos e temores, suas alegrias, medos e sofreguidão, tudo isso não pode ser condensado em uma equação técnica legal, numa logicidade matemática, numa subsunção sentencial de rigorismo silogístico impensável nos dias em que correm. A vida, em alguns momentos, não é lógica; é intrigante, misteriosa com seus entroncamentos. $\mathrm{O}$ julgamento de uma alteração de prenome deve ter esta realidade como bússola, e como fim a dignidade da pessoa humana.

Propõe-se a ampliar ao máximo o conteúdo da expressão 'exposição ao ridículo', em torno da qual se sente violada, máxime porque a tutela ao prenome deita suas raízes na tábua axiológica constitucional alicerçada no princípio fundante da dignidade humana. Quanto ao julgador, na dúvida, ser-lhe-ia recomendável - e até imperativo - levar em conta que, na inteligência das garantias constitucionais, não cabe a interpretação restritiva; favorabilia amplianda. Disso resulta a necessidade de uma nova posição no julgamento, sem tecnicismos debalde amparados em um legalismo fossilizado, sem utilidade sociall $^{15}$.

Ademais, os princípios humanísticos que devem guiar a atividade do juiz, bem como toda a esfera forense, estão imbuídos na ementa da Ministra Nancy Andrighi do Superior Tribunal de Justiça, que vem servindo de precedente para

\footnotetext{
${ }_{14}$ VIEIRA, Tereza Rodrigues. Mudanças ou alterações no nome civil das pessoas físicas. 1989. 170f. Dissertação (Mestrado) - Pontifícia Universidade Católica, São Paulo,1989.

15 PEREIRA, Ézio. Alteração do prenome. Leme: Edijur, 2006, p. 58.
} 


\section{várias decisões em prol da alteração do registro civil de transexuais operados e ilustra de forma contundente o caráter bioético e reformador que os novos tempos pedem do direito brasileiro, in verbis:}

Direito civil. Recurso especial. Transexual submetido à cirurgia de redesignação sexual. Alteração do prenome e designativo de sexo. Princípio da dignidade da pessoa humana.

- Sob a perspectiva dos princípios da Bioética - de beneficência, autonomia e justiça -, a dignidade da pessoa humana deve ser resguardada, em um âmbito de tolerância, para que a mitigação do sofrimento humano possa ser o sustentáculo de decisões judiciais, no sentido de salvaguardar o bem supremo e foco principal do Direito: o ser humano em sua integridade física, psicológica, socioambiental e ético-espiritual.

- A afirmação da identidade sexual, compreendida pela identidade humana, encerra a realização da dignidade, no que tange à possibilidade de expressar todos os atributos e características do gênero imanente a cada pessoa. Para o transexual, ter uma vida digna importa em ver reconhecida a sua identidade sexual, sob a ótica psicossocial, a refletir a verdade real por ele vivenciada e que se reflete na sociedade.

- A falta de fôlego do Direito em acompanhar o fato social exige, pois, a invocação dos princípios que funcionam como fontes de oxigenação do ordenamento jurídico, marcadamente a dignidade da pessoa humana - cláusula geral que permite a tutela integral e unitária da pessoa, na solução das questões de interesse existencial humano.

- Em última análise, afirmar a dignidade humana significa para cada um manifestar sua verdadeira identidade, o que inclui o reconhecimento da real identidade sexual, em respeito à pessoa humana como valor absoluto.

- Somos todos filhos agraciados da liberdade do ser, tendo em perspectiva a transformação estrutural por que passa a família, que hoje apresenta molde eudemonista, cujo alvo é a promoção de cada um de seus componentes, em especial da prole, com o insigne propósito instrumental de torná-los aptos de realizar os atributos de sua personalidade e afirmar a sua dignidade como pessoa humana.

- A situação fática experimentada pelo recorrente tem origem em idêntica problemática pela qual passam os transexuais em sua maioria: um ser humano aprisionado à anatomia de homem, com o sexo psicossocial feminino, que, após ser submetido à cirurgia de redesignação sexual, com a adequação dos genitais à imagem que tem de si e perante a sociedade, encontra obstáculos na vida civil, porque sua aparência morfológica não condiz com o registro de nascimento, quanto ao nome e designativo de sexo.

- Conservar o "sexo masculino" no assento de nascimento do recorrente, em favor da realidade biológica e em detrimento das realidades psicológica e social, bem como morfológica, pois a aparência do transexual redesignado, em tudo se assemelha ao sexo feminino, equivaleria a manter o recorrente em estado de anomalia, deixando de reconhecer seu direito de viver dignamente. 
- Assim, tendo o recorrente se submetido à cirurgia de redesignação sexual, nos termos do acórdão recorrido, existindo, portanto, motivo apto a ensejar a alteração para a mudança de sexo no registro civil, e a fim de que os assentos sejam capazes de cumprir sua verdadeira função, qual seja, a de dar publicidade aos fatos relevantes da vida social do indivíduo, forçosa se mostra a admissibilidade da pretensão do recorrente, devendo ser alterado seu assento de nascimento a fim de que nele conste o sexo feminino, pelo qual é socialmente reconhecido.

- Vetar a alteração do prenome do transexual redesignado corresponderia a mantê-lo em uma insustentável posição de angústia, incerteza e conflitos, que inegavelmente atinge a dignidade da pessoa humana assegurada pela Constituição Federal. No caso, a possibilidade de uma vida digna para o recorrente depende da alteração solicitada. $\mathrm{E}$, tendo em vista que o autor vem utilizando o prenome feminino constante da inicial, para se identificar, razoável a sua adoção no assento de nascimento, seguido do sobrenome familiar, conforme dispõe o art. 58 da Lei n. ${ }^{\circ} 6.015 / 73$.

- Deve, pois, ser facilitada a alteração do estado sexual, de quem já enfrentou tantas dificuldades ao longo da vida, vencendo-se a barreira do preconceito e da intolerância. O Direito não pode fechar os olhos para a realidade social estabelecida, notadamente no que concerne à identidade sexual, cuja realização afeta o mais íntimo aspecto da vida privada da pessoa. E a alteração do designativo de sexo, no registro civil, bem como do prenome do operado, é tão importante quanto a adequação cirúrgica, porquanto é desta um desdobramento, uma decorrência lógica que o Direito deve assegurar.

- Assegurar ao transexual o exercício pleno de sua verdadeira identidade sexual consolida, sobretudo, o princípio constitucional da dignidade da pessoa humana, cuja tutela consiste em promover o desenvolvimento do ser humano sob todos os aspectos, garantindo que ele não seja desrespeitado tampouco violentado em sua integridade psicofísica. Poderá, dessa forma, o redesignado exercer, em amplitude, seus direitos civis, sem restrições de cunho discriminatório ou de intolerância, alçando sua autonomia privada em patamar de igualdade para com os demais integrantes da vida civil. A liberdade se refletirá na seara doméstica, profissional e social do recorrente, que terá, após longos anos de sofrimentos, constrangimentos, frustrações e dissabores, enfim, uma vida plena e digna.

- De posicionamentos herméticos, no sentido de não se tolerar 'imperfeições' como a esterilidade ou uma genitália que não se conforma exatamente com os referenciais científicos, e, consequentemente, negar a pretensão do transexual de ter alterado o designativo de sexo e nome, subjaz o perigo de estímulo a uma nova prática de eugenia social, objeto de combate da Bioética, que deve ser igualmente combatida pelo Direito, não se olvidando os horrores provocados pelo holocausto no século passado. Recurso especial provido"16.

${ }_{16}$ BRASIL. Supremo Tribunal de Justiça. Recurso Especial 1008398/SP - São Paulo. Relatora: Ministra Nancy Andrighi. Pesquisa de Jurisprudência. Disponível em: http://www.stj.jus.br/SCON. Acesso em: 19 maio. 2015. 
Além do fim social, há de se levar em conta também o princípio da veracidade do registro público. Ora, se o transexual operado de fato possui um gênero diverso daquele constante em seu registro primeiro, a imutabilidade deste registro tornaria o próprio falso.

\subsection{EFEITOS DA TRANSGENITALIZAÇÃO NO CASAMENTO E FILIAÇÃO}

Em princípio, as núpcias de transexuais não encontram impeditivos legais per se. Ainda que uma de suas funções seja dar amparo jurídico às relações sexuais dos nubentes, bem como à criação e educação da prole destas advinda ${ }^{17}$ entende-se que tal preceito não deve passar por uma interpretação gramatical. Se assim não fosse, não seria possível o casamento entre pessoas impotentes e/ou inférteis ou idosas ao ponto de não se sentirem confortáveis em manter relações sexuais.

Tal posição do direito brasileiro fica bem clara no caso do casamento com pessoa impotente: ao mesmo tempo em que o Código Civil prevê que a anulabilidade do casamento pode ser arguida se a impotência ou infertilidade for descoberta posteriormente ao ato cível, ele não obsta o casamento no caso de ela ser conhecida por ambos os cônjuges antes do mesmo.

Além disso, tendo o transexual operado alterado seu registro civil, não há confusão sobre o seu sexo jurídico, tampouco sobre o preenchimento do prérequisito nupcial da diversidade de sexo, quando do seu casamento. Na situação em que se quede inalterado o registro civil, por conseguinte, o referido pré-requisito tratará de vedar o casamento, pois este se configuraria homossexual, e tal instituto ainda não é previsto pelo ordenamento pátrio, apesar de se apresentar como tendência jurídica.

Faz-se necessário ressaltar a necessidade do transexual operado comunicar ao seu parceiro sobre a sua condição antes do casamento, para que este não fique sujeito à anulação mediante invocação por parte do cônjuge enganado de erro essencial sobre a pessoa operada. O erro advindo do desconhecimento de tal condição põe em cheque o consentimento dado pela parte dela desconhecida, viciando-o, como aduz Orlando Gomes:

[...] às qualidades estritamente inerentes à pessoa, não só em seus atributos físicos mas, também, civis e sociais, sempre que a insciência seja tal que faça da pessoa uma individualidade diferente das outras

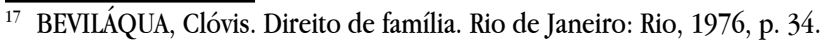


ou que incida sobre qualidades tão importantes que, se conhecida sua falta, o consentimento não seria dado ${ }^{18}$.

O artigo 1.557 do Código Civil pátrio arrola as hipóteses de erro essencial sobre a pessoa do outro cônjuge, in verbis

Art. 1.557. Considera-se erro essencial sobre a pessoa do outro cônjuge:

I - o que diz respeito à sua identidade, sua honra e boa fama, sendo esse erro tal que o seu conhecimento ulterior torne insuportável a vida em comum ao cônjuge enganado;

II - a ignorância de crime, anterior ao casamento, que, por sua natureza, torne insuportável a vida conjugal;

III - a ignorância, anterior ao casamento, de defeito físico irremediável, ou de moléstia grave e transmissível, pelo contágio ou herança, capaz de pôr em risco a saúde do outro cônjuge ou de sua descendência;

IV - a ignorância, anterior ao casamento, de doença mental grave que, por sua natureza, torne insuportável a vida em comum ao cônjuge enganado (grifo nosso).

Os incisos destacados referem-se aos erros aos quais estão sujeitos os transexuais operados que não informam aos parceiros sobre a sua operação. $O$ inciso I e III tratam, respectivamente, do que parte da doutrina chama de identidade e identidade física ${ }^{19}$. Sobre os outros, entende-se que não cabe discutir pois, em resposta ao inciso II, como previamente discutido, a operação não constitui crime nem para o transexual nem para o médico, e, em resposta ao inciso IV, o transexualismo, ainda que efetivamente se configure como doença mental, terá seus efeitos largamente reduzidos ou anulados após a operação, pois esse é o objetivo da mesma, em primeiro lugar, não subsistindo a gravidade mencionada no texto legal.

Ressalta-se que, para a anulação, não basta que haja a descoberta $a$ posteriori da condição do transexual, mas esta também tem de tornar a vida em comum insuportável. Se houver interesse na dissolução do casamento mesmo por parte de um dos cônjuges, mas este ter conhecimento de que o outro era transexual desde antes das núpcias, a ação intentada deverá ser a de divórcio, que segue os ditames do divórcio de pessoas de sexo diverso ${ }^{20}$.

Nos casos de transexual que realiza a operação e altera seu registro civil na constância do casamento, o casamento se torna inexistente por sobrevir à condição

18 GOMES, Orlando. Direito de família. Rio de Janeiro: Forense, 1981, p. 83.

${ }^{19}$ MONTEIRO, Washington de Barros. Curso de direito civil.: Direito de família. São Paulo: Saraiva, 1980 , p. 84.

20 SZANIAWSKI, Elimar. Op. cit. 
de um casamento entre pessoas do mesmo sexo. Ainda assim, uma vez considerada a plena comunhão familiar que o casamento prevê, o transexual casado que deseja ter seu sexo redesignado necessita do consentimento do seu cônjuge para fazê-lo. Nesse contexto, uma operação não consentida é causa mais do que justificada para o outro cônjuge exigir o divórcio ${ }^{21}$. Claro que tal situação só seria vista no caso de tal casamento continuar existente e válido ${ }^{22}$, ideia aqui oposta. Partilha-se do pensamento do douto Elimar Szaniaswki que, ao contemplar tal cenário, advoga:

O transexual casado, que venha a se submeter à operação de mudança de sexo na constância do casamento, deverá providenciar, previamente, o divórcio e zelar pela segurança e bem-estar econômico e social de seu cônjuge e de filhos incapazes.

$\mathrm{Na}$ hipótese de o indivíduo não ter providenciado o prévio divórcio e que tenha se operado, mantendo o casamento, propomos, de lege ferenda, ao ser requerida a mudança de estado sexual e do prenome no assento de nascimento, deva o juiz que conhecer do pedido, no mesmo processo judicial que deferir a redesignação do prenome e do estado sexual, decretar o divórcio, em procedimento incidental, dissolvendo o matrimônio do transexual operado com seu cônjuge heterossexual..$^{23}$

No tocante às relações de filiação anterior à redesignação cirúrgica, a doutrina é consideravelmente pacífica em entender que os registros dos filhos não serão alterados, aqui sim prevalecendo o princípio anteriormente debatido da irretroatividade do registro civil $^{24}$.

\section{CONCLUSÃO}

Conclui-se que há muitos avanços a serem feitos no que diz respeito à garantia dos direitos dos indivíduos que passam por uma cirurgia de transgenitalização. Direitos inatos como a dignidade e a saúde transcendem legislações pátrias, logo, é mandatório que uma democracia do século XXI se mostre preparada para proteger esses cidadãos.

Considerando a condição de doença do transexualismo, o direito do transexual em ter saúde vê-se fundamentado no princípio bioético da beneficência.

${ }^{21}$ CAHALI, Yussef. Divórcio e separação. São Paulo: Revista dos Tribunais, 1987, p. 249.

${ }^{22}$ BÉNABENT, Alain. Droit civil. La famille. Paris: Litec, 1997, p. 67.

${ }^{23}$ SZANIAWSKI, Elimar. Op. cit. 1998.

${ }^{24}$ VIEIRA, Tereza Rodrigues. Op. cit., 2008, p. 316. 
Da mesma forma, o princípio da autonomia, isto é, do direito das pessoas de escolherem dispor ou não de seu dentro dos limites éticos e do respeito a essa decisão por parte de médicos e outros profissionais envolvidos, também serve de base bioética para a cirurgia ${ }^{25}$. O princípio da justiça vai mais além, ditando que a cirurgia não só é aprovável, como pode ser custeada pelo governo, a exemplo de tantas outras intervenções cirúrgicas de diversas ordens ${ }^{26}$.

Resta claro que novas diretrizes, principalmente no tocante à legislação, fazem-se mister no sentido de transformar a realidade dos transexuais brasileiros. É lamentável a demora do Poder Legislativo em debater os projetos de lei que versam sobre a matéria aqui abordada, porém, corajosos textos jurisprudenciais como o supracitado vêm solucionando esta lacuna, o que, em termos bioéticos, é extremamente positivo.

\section{REFERÊNCIAS}

BÉNABENT, Alain. Droit civil. La famille. Paris: Litec, 1997.

BEVILÁQUA, Clóvis. Direito de família. Rio de Janeiro: Rio, 1976.

BRASIL. Supremo Tribunal de Justiça. Recurso Especial 1008398/SP - São Paulo. Relatora: Ministra Nancy Andrighi. Pesquisa de Jurisprudência. Disponível em: $<$ http://www.stj.jus.br/SCON> . Acesso em: 19 maio. 2015.

CAHALI, Yussef. Divórcio e separação. São Paulo: Revista dos Tribunais, 1987.

CONSELHO FEDERAL DE MEDICINA. Resolução $\mathrm{n}^{\mathrm{O}} 1.482$ de 10 de setembro de 1997. Disponível em: <http://www.portalmedico.org.br/resolucoes/ CFM/1997/1482_1997.htm > . Acesso em: 19 maio. 2015.

CONSELHO FEDERAL DE MEDICINA. Dispõe sobre a cirurgia de transgenitalismo e revoga a Resolução CFM n ${ }^{0} 1.482 / 97$. Resolução $n^{0} 1.652$ de 6 de novembro de 2002. Disponível em: <http://www.portalmedico.org.br/resolucoes/ CFM/2002/1652_2002.htm >. Acesso em: 19 maio. 2015.

\footnotetext{
${ }^{25}$ MARTINS, Rode Anélia. Transexualismo: aspectos jurídicos e bioéticos, 2011. Disponível em: <http:/tjsc25. tjsc.jus.br/academia/artigos/escolha.php?escolha=1>. Acesso em: 13 ago. 2012.

26 VIEIRA, Tereza Rodrigues. O direito do transexual e a bioética. Jus Navigandi, Teresina, ano 8, n. 125, 2003. Disponível em: < http://jus.com.br/revista/texto/4354> . Acesso em: 13 ago. 2012.
} 
CONSELHO FEDERAL DE MEDICINA. Dispõe sobre a cirurgia de transgenitalismo e revoga a Resolução CFM $\mathrm{n}^{0} 1.652 / 02$. Resolução $\mathrm{n}^{0} 1.955$ de 12 de agosto de 2010. Disponível em: <http://www.portalmedico.org.br/resolucoes/ CFM/2010/1955_2010.htm > . Acesso em: 19 maio. 2015.

COSTA, Renato Pamplona da. Os onze sexos. São Paulo: Gente, 1997.

GOMES, Orlando. Direito de família. Rio de Janeiro: Forense, 1981.

MARTINS, Rode Anélia. Transexualismo: aspectos jurídicos e bioéticos. Academia Judicial. Florianópolis, 2011. Disponível em: <http:/tjsc25.tjsc.jus.br/academia/ arquivos/transexualismo_rode_martins.pdf $>$. Acesso em: 19 maio. 2015.

MONTEIRO, Washington de Barros. Curso de direito civil: direito de família. São Paulo: Saraiva, 1980.

NUCCI, Guilherme de Souza. Código penal comentado. São Paulo: Revista dos Tribunais, 2006.

PEREIRA, Ézio. Alteração do prenome. Leme: Edijur, 2006.

SZANIAWSKI, Elimar. Limites e possibilidades do direito de redesignação do estado sexual. São Paulo: Revista dos Tribunais, 1998.

VIEIRA, Tereza Rodrigues. Aspectos psicológicos, médicos e jurídicos do transexualismo. Psicólogo informação, São Paulo, nº 4, p. 75, 2000.

VIEIRA, Tereza Rodrigues. Mudanças ou alterações no nome civil das pessoas físicas. 1989. 170f. Dissertação (Mestrado em Direito) - Pontifícia Universidade Católica de São Paulo, São Paulo, 1989.

VIEIRA, Tereza Rodrigues. Nome e sexo: mudanças no registro civil. São Paulo: Revista dos Tribunais, 2008.

VIEIRA, Tereza Rodrigues. O direito do transexual e a bioética. Jus Navigandi. Teresina, 2003. Disponível em: < http://jus.com.br/revista/texto/4354 > Acesso em: 19 maio. 2015. 